OPEN ACCESS

Edited by: Rob Harcourt,

Macquarie University, Australia

Reviewed by:

Christian T. K.-H. Stadtlander, Independent Researcher, St. Paul,

United States

Melina Kourantidou

Dalhousie University, Canada

*Correspondence:

Paul Hedge

paul.hedge@csiro.au

Specialty section:

This article was submitted to Marine Affairs and Policy,

a section of the journal

Frontiers in Marine Science

Received: 10 January 2020 Accepted: 08 June 2020

Published: 30 July 2020

Citation:

Hedge P, van Putten El, Hunter C and Fischer M (2020) Perceptions,

Motivations and Practices

for Indigenous Engagement in Marine

Science in Australia.

Front. Mar. Sci. 7:522.

doi: 10.3389/fmars.2020.00522

\section{Perceptions, Motivations and Practices for Indigenous Engagement in Marine Science in Australia}

\author{
Paul Hedge ${ }^{1 *}$, Elizabeth Ingrid van Putten ${ }^{2,3}$, Cass Hunter ${ }^{4}$ and Mibu Fischer ${ }^{5}$ \\ ${ }^{1}$ Institute for Marine and Antarctic Studies, University of Tasmania, Hobart, TAS, Australia, ${ }^{2}$ Oceans and Atmosphere, \\ CSIRO, Hobart, TAS, Australia, ${ }^{3}$ Centre for Marine Socioecology, University of Tasmania, Hobart, TAS, Australia, ${ }^{4}$ Oceans \\ and Atmosphere, CSIRO, Cairns, QLD, Australia, ${ }^{5}$ Oceans and Atmosphere, CSIRO, Brisbane, QLD, Australia
}

Australian science has evolved to include a number of initiatives designed to promote and guide ethical and culturally appropriate Indigenous participation and engagement. While interest and overall engagement between Indigenous people and marine scientists appears to have grown in the last decade there are also signs that some researchers may not be setting out to engage with Indigenous Australians on the right foot. This research seeks to move beyond anecdotal evidence about engagement of marine researchers with Indigenous Australians by gathering empirical information from the scientists' perspective. Our survey of 128 respondents showed that $63 \%$ ( $n=79$ ) of respondents have engaged with Indigenous communities in some way throughout their career, however, most marine research projects have not included Indigenous engagement and when it occurs it is often shorter than 3 years in duration. Responses indicated that the majority of marine scientists see mutual benefits from engagement, do not avoid it and believe it will become more important in the future. We identify a number of challenges and opportunities for marine research institutions, marine researchers and Indigenous communities if positive aspirations for engagement are to be converted to respectful, long-term and mutually beneficial engagement.

Keywords: Indigenous engagement, marine science, Australia, perceptions, research motivations, research practices

\section{INTRODUCTION}

The United Nations Declaration on the Rights of Indigenous Peoples (United Nations, 2008) is a landmark international policy instrument that recognizes the importance of Indigenous culture, practices and knowledge. Member states that are signatory to the policy commit to recognize Indigenous rights and to act in ways that convert commitment to meaningful outcomes. Following its ratification, the United Nations (UN) committed to develop a number of supporting or complementary international policy instruments for setting directions and benchmarks for Indigenous engagement and participation in research on social-ecological systems. The UN Convention on Biological Diversity provides The Tkarihwaié:ri; Code of Ethical Conduct to ensure respect for the cultural and intellectual heritage of Indigenous and local communities (Convention on Biological Diversity, 2011); the Intergovernmental Platform on Biodiversity and Ecosystem 
Services (IPBES) has developed approaches and procedures for building Indigenous knowledge into biodiversity and ecosystem services assessments (Thaman et al., 2013; IPBES, 2017); and the UN Educational, Scientific and Cultural Organization (UNESCO) is developing its policy on engaging with Indigenous peoples to outline a consistent approach that will guide all of its program sectors in their interactions with Indigenous people (UNESCO, 2018).

Australia is a signatory to the UN Declaration on Rights of Indigenous Peoples, has ratified the Convention on Biological Diversity and is a member state of UNESCO and IPBES. This commitment to international conventions is one part of a multilevel approach that guides and directs the Australian research sector to recognize the importance of Indigenous culture, practice and knowledge. After France and the United States, Australia has the third largest marine territory in the world, it is also home to the longest living Indigenous culture on earth and asserts itself as a marine nation (National Marine Science Committee, 2015). Australia is one of the global leaders in marine science, biodiversity conservation and sustainable use of marine resources (National Marine Science Committee, 2015). Australia's Indigenous people are custodians and active environmental managers with rights and interests recognized formally to varying extents in well over half of Australia's land area (Hill et al., 2013) and rightfully demand inclusion in decision making related to research, planning and management (Ens et al., 2012; Nursey-Bray and Jacobson, 2014; Dobbs et al., 2016). Commitment to international agreements, enduring Indigenous culture and leadership in marine management and science combine to make Australia a good case study for ground-truthing the status of Indigenous engagement in marine research.

International policy instruments, such as The Tkarihwaié:ri (Convention on Biological Diversity, 2011) and the UNESCO policy for engaging with Indigenous peoples (UNESCO, 2018), contribute to helping Australians recognize the importance of Indigenous culture, practices and knowledge. A variety of initiatives have been initiated by Australian institutions to promote and guide ethical Indigenous participation and engagement. For example: the Australian Institute of Aboriginal and Torres Strait Islander Studies provide Guidelines for Ethical Research in Australian Indigenous Studies (AIATSIS, 2012); national marine research agencies have developed Indigenous engagement strategies (e.g., AIMS, 2020; CSIRO, 2020); and universities and administrators of research grants have established guidelines for engagement (Sithole, 2012; Australian Government, 2014) or identified Indigenous research priorities to direct research investments (FRDC, 2013). Indigenous land councils have provided guidance on how researchers and others should engage with Indigenous communities. A recent and comprehensive example has been developed for research planning and implementation in the Kimberley region of Western Australia (Lincoln et al., 2017). A growing body of academic literature provides insightful principles and theoretical frameworks to guide approaches to engaging with Indigenous Australians (e.g., Carter, 2008; Hill et al., 2012; Jackson et al., 2012), use of Indigenous knowledge (e.g., Rigney, 2001; Green et al., 2010; Bohensky et al., 2013) and use of appropriate communication tools (e.g., Jones et al., 2008).

Both Indigenous communities and researchers have important roles in identifying challenges, seeking opportunities and developing productive relationships. During the last decade the interest and overall engagement between Indigenous people and marine scientists has grown with an increasing number of examples of productive, collaborative and empowering approaches to Indigenous heritage management (Mitchell et al., 2013). Many environmental scientists endorse the participation of Indigenous communities in research that connects the natural and cultural components of sustainability (Carter, 2008). The accelerating integration of Indigenous knowledge with marine science in recent years, is seen as part of a marked recoupling of Indigenous relationships with traditional lands and sea country throughout Australia (Bohensky et al., 2013). Increased Indigenous engagement is evidenced by including Indigenous interests in Australia's marine bioregional plans (e.g., Australian Government, 2012) and marine park management plans (e.g., Australian Government, 2018), the development of an increasing number of sea country plans (e.g., Smyth and Bahrdt Consultants, 2004; Pilbara Indigenous Marine Reference Group, 2010; Dhimurru Aboriginal Corporation, 2013) and the increase in number and area of Indigenous protected areas (Jackson et al., 2017).

While there are signs of increasing Indigenous engagement in marine science, there are also signs that researchers may not be setting out to engage with Indigenous Australians on the right foot (e.g., Smith, 1999; Bainbridge et al., 2015). For example, inadequate attempts at involving Indigenous people in the decision-making processes across all stages of research projects, unrealistic project time frames for effective engagement, and a lack of goodwill to understand how to effectively engage with the values, priorities and knowledge of Indigenous people have been reported as reasons for lack of meaningful Indigenous participation (Ens et al., 2012; Ayre and Mackenzie, 2013; Crook et al., 2016). Some have suggested that participatory environmental research programs in Australia offer Indigenous communities passive participation, such as consultation or information leaflets without the opportunity for a more active engagement or participation (Carter, 2008).

Indigenous engagement in environmental management can be classified by the combination of arrangements for power sharing, participation and inter-cultural purpose (Hill et al., 2012). The same authors proposed a typology of Indigenous engagement that ranges from "Agency governance" to "Indigenous co-governance," and noted that shifting toward Indigenous co-governance requires changes in power sharing, the level of participation and focus on intercultural engagement. A shift toward Indigenous cogovernance arrangements in the marine research sector represents a new research regime that is likely to present challenges and opportunities to marine researchers and the institutional arrangements to which they have become 
accustomed. For example, establishing effective arrangements for participation of Indigenous people in prioritizing allocation of resources for research and monitoring (Ens et al., 2012), ensuring projects are designed and resourced to provide for effective cross-cultural engagement and establishing legal agreements to protect and manage Indigenous knowledge (Janke and Sentina, 2018).

Access to fit-for-purpose evidence is an important requirement for effectively assessing Australia’s performance in moving toward the UN benchmarks for Indigenous engagement and participation in research on social-ecological systems. Published literature on how, when and if marine researchers are engaging with Indigenous people (as part of their research) is hard to find. The authors could not find any publicly available data on the status and trends of scientists' practices in engagement and their perspectives on motivations for and benefits from engagement. Without these evidence-based insights, Indigenous Australians and the marine science sector are both disadvantaged in facing up to the challenges and opportunities of engagement.

This paper seeks to move beyond anecdotal evidence about engagement of marine researchers with Indigenous Australians and contribute to an evidence-base to inform discussions about practices, performance and opportunities for improvement. In this paper, we present empirical information gathered from scientists, recognizing this is one part of understanding the larger sphere of building culturally appropriate engagement with Indigenous Australians.

\section{MATERIALS AND METHODS}

A survey was designed to understand the extent to which marine researchers engage with Indigenous communities in Australia, and the form that this engagement takes. Before the final survey was applied, the survey was pre-tested by interviewing 10 marine scientists selected on the basis of the diversity of their engagement experience. Feedback received from the marine scientists was used to refine and improve the survey. The final survey was launched online on 17 April 2017 using the Survey Monkey software, the final response was received on 26 June 2017. All survey data were managed in accordance with the Human Ethics Approval provided by the CSIRO Human Ethics Committee (137/16).

The online questionnaire contained four sections (see online Supplementary Material for contextual text and questionnaire). The first section (questions 1-7) collected demographic information from the respondent and their area of marine research. In the second section (questions 8-21) the respondent's history of engagement was established, including the frequency and their own role in the engagement. Section three (questions 22-28) ascertained the respondent's perceptions of engagement. The last section (questions 29-36) was focused on understanding the respondent's efforts and interest in increasing and/or improving engagement in the future.

To ensure that there was a common understanding among respondents of the interpretation of Indigenous engagement, the following definition of the term was adopted: Efforts by researchers to inform, consult or involve Aboriginal and Torres Strait Islander people in marine research.

The project team collaborated with marine science societies (i.e., Australian Marine Science Society, Australian Coral Reef Society, Australian Society for Fish Biology, Australian Chondrichthyan Society and Australian Meteorological and Oceanography Society), marine science institutions (e.g., CSIRO, Geoscience Australia, Australian Institute of Marine Science) and government agencies (e.g., New South Wales Department of Primary Industries and Western Australian Department of Parks and Wildlife) to promote participation in the survey. An email introducing the survey was sent to key people in these organizations, who were asked to forward the survey on to their members, as per prior arrangement.

The survey data were analysed and a mixed-effects logit model developed to predict researcher engagement. The glmer routine was used in $\mathrm{R}$ (version 3.5.0) (Bates et al., 2014) for model development. Engagement was explained by two groups of variables: age and research experience, and perceptions of engagement (see Tables 1, 2). The data was then limited to only those respondents who had engaged before $(n=79)$ to determine if there were any characteristics within this group that could be typified. For instance, it was hypothesized that more junior people may have had different roles or different engagement opportunities. Simple statistical tests of difference were used to determine these types of population characteristics.

\section{RESULTS}

\section{Experience and Demographics}

In total, 128 survey responses $(n=128)$ were received between April-June 2017. The total number of responses represents approximately $5 \%$ of marine scientists in Australia (National Marine Science Committee, 2015). Although this is a relatively small proportion of the total population of marine scientists in Australia and we cannot statistically infer characteristics for the entire marine research population (i.e., we adopted a non-probability approach to sampling design that did not satisfy the requirements of a random or model-based sampling design) we expect our survey results to be representative of the broader status of Indigenous engagement across Australia's marine science sector. We do, however, acknowledge that the survey may be biased toward the characteristics of scientists who are members of the associations and government agencies targeted to promote participation in the survey.

Survey respondents were from a range of institutions, including government science agencies (36\%), State government agencies (34\%), Universities (48\%), environmental non-government organizations and consultancies (collectively accounting for less than $8 \%)$. The gender distribution was $54 \%$ male and $46 \%$ 
female, which mirrors Australia's gender distribution in marine science (Data Source: 2011 Census on Population and Housing ${ }^{1}$. Aboriginal and Torres Strait Islanders represented $3.2 \%$ of survey responses. It is unknown if this resembles the proportion of Indigenous marine research scientists in Australia as we were unable to find any information on this.

Data showed that survey respondents where practicing in the fields of conservation (9\%), ecology (38\%), biology (16\%), fisheries (22\%) aquaculture (2\%), social sciences $(4 \%)$, multi-disciplinary science (9\%), and management (15\%). The remaining 10 respondents were in smaller percentages spread across marine spatial analysis, modeling and geomorphology. Responses were dominated by natural scientists as opposed to social or inter-disciplinary scientists.

\section{Characterizing Marine Researchers Who Engage With Indigenous Communities}

Results show that $63 \%(n=79)$ of respondents have engaged with Indigenous communities in some way throughout their career. Despite the relatively high proportion of researchers indicating they have engaged over their career, most marine research projects have not included engagement (Figure 1) and when it does occur it is often shorter than 3 years in duration (Figure 2).

The majority $(68 \%)$ of respondents who had engaged Indigenous communities in research are aged between 31 and 50 years. Approximately half of the $31-50$ year olds $(n=27)$ identified as either senior researchers or science program managers. Marine researchers have used a variety of mechanisms to engage, but around $80 \%$ of those who engaged stated they had visited "country" . Visits to county provide researchers with face-to-face inter-cultural experiences that deepen understanding about how to respectfully engage with Indigenous communities. The vast majority of visits to country occurred in northern and western parts of Australia, including Torres Strait and the Great Barrier Reef in Queensland. Engagement involving visits to country in south and south-eastern parts of Australia accounted for only $16 \%$ of reported visits to country.

Survey respondents who have engaged with Indigenous communities $(n=77)$ have collectively engaged across the spectrum of stages in research projects with the most common of these being conducting field work and collecting data (Figure 3). The spectrum of stages shown in Figure 3 reflect different stages in which most projects are carried out (going from starting the project at the bottom of Figure 3 to finishing on the top). What is apparent is that engagement is heavily weighted toward the middle stages of projects with much less emphasis at the early and final stages. Almost three quarters of respondents (56-74\%) who had engaged were doing this in relation to data collection and $64 \%$ in conducting fieldwork (which may be seen as a complimentary activity). Engagement in the early

\footnotetext{
${ }^{1}$ https://auth.censusdata.abs.gov.au/webapi/jsf/dataCatalogueExplorer.xhtml

${ }^{2}$ For Aboriginal and Torres Strait Islander people "country" does not just mean the creeks, rock outcrops, hills and waterholes, sea's, beaches, reefs and estuaries. "Country" includes all living things. It incorporates people, plants and animals. It embraces the seasons, stories and creation spirits. "Country" is both a place of belonging and a way of believing.
}

stages of projects is relatively low with about a quarter of respondents $(27 \%)$ engaging to secure research funds, less than half $(48 \%)$ engaging to scope project objectives and fewer again engaging to develop formal agreements (39\%) for projects. These early stages of projects are where the outcomes and benefits (mutual or otherwise) that flow from research are conceived and agreed. There is little engagement with Aboriginal and/or Torres Strait Islander people in developing academic publications and analyzing data, which could be seen as a missed opportunity in terms of capacity building and science engagement, and also a lack of respect. Lastly the low engagement on project review would also seem an opening for improvement as feedback from communities was viewed as helpful by $66 \%$ of respondents for making refinements to research or with subsequent engagements.

\section{What Sets Those Who Engage Apart From Those Who Do Not?}

To find out if respondents who engaged (coded as 1 ) and those who do not engage (coded as 0 ) with Aboriginal and/or Torres Strait Islander communities could be characterized (question 8) we developed a logit model (Hosmer et al., 2013). ${ }^{3}$ Perceptions were assessed against respondents' age (question 6), who researchers believe should carry responsibility for engagement (question 25), if they had tried to develop understanding about how to engage (question 29), willingness to alter research based on feedback from engagement (question 26), and whether or not respondents believed the importance of engagement, partnering and involving Indigenous people in their research will become more important in the future (question 36) (Table 1).

A mixed-effects analysis was applied using a generalized linear mixed model fit by maximum likelihood. A random effect associated with ID is included to describe variation among individuals in terms of their overall propensity to respond positively to past engagement (Table 2). Pearson's correlation coefficient was high between the years of experience and age of the researchers, we therefore excluded one of these variables from the analysis. The final model contained five variables that explain what sets marine researchers who engaged with Aboriginal and/or Torres Strait Islander communities apart from those who have not.

Whether respondents had tried to develop understanding about how to engage with Aboriginal and/or Torres Strait Islander people was the statistically most significant predictor of a positive response to having engaged in the past. The next most significant predictor of past engagement was that the respondent was prepared to alter their research if feedback from an Aboriginal and/or Torres Strait Islander person included a request for change. There was some evidence that if respondents believed that engagement was likely to become more important in the future this predicted their past engagement. Another significant predictor of past engagement was if respondents believed the principal investigator was the one who should be responsible for engagement then individual engagement was lessened. There was weak evidence that older age was

${ }^{3}$ Because only responses were used that had no missing values, the number of observations was 101 for the mixed effects model. 


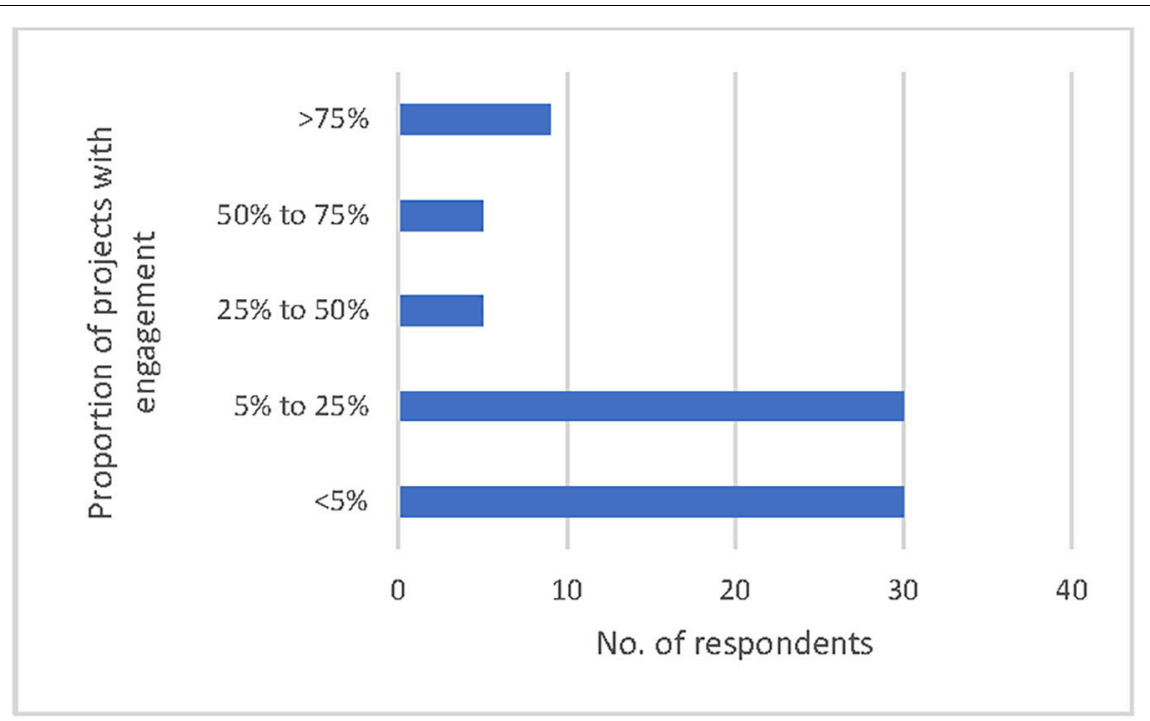

FIGURE 1 | Marine research projects over a scientist's career to date (i.e., up to 26 June 2017) that included Indigenous engagement measured by number of survey respondents.

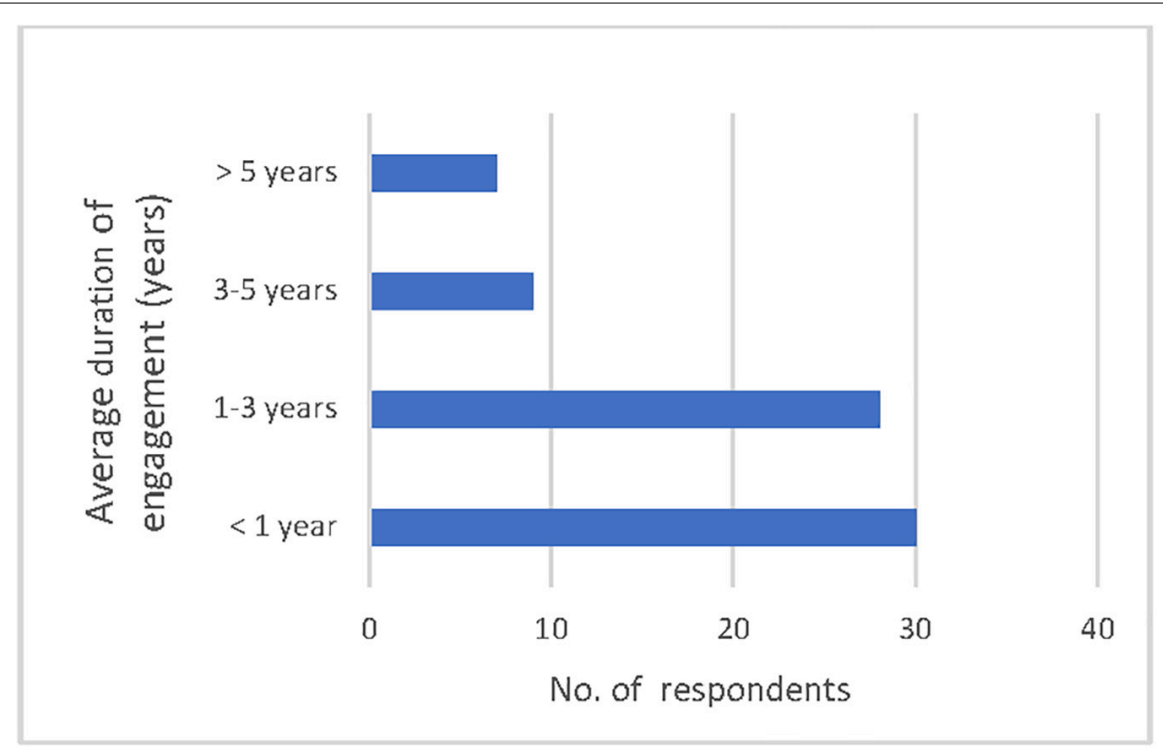

FIGURE 2 | Average duration of Indigenous engagements in marine research projects measured by number of survey respondents.

associated with lower levels of past engagement. This is perhaps surprising given the additional opportunities that older researchers would have had to engage over the course of their (typically longer) careers.

\section{Perceptions and Motivation}

For the full sample of survey respondents (i.e., including respondents who had engagement and those who had not, $n=128)$, results show that the vast majority (91\%) of researchers think the benefits of Indigenous engagement in marine research extend beyond the researchers (question 24): $59 \%$ indicating that both Indigenous communities and researchers benefit from Indigenous engagement in marine research; and 32\% indicating that benefits extend to everyone in Australia. Motivations for engagement are likely to be influenced by a broad range of factors. Respondents where provided with eight answer options to select from with the view that this would represent an informative but simplistic perspective on motivations. When provided the option of identifying multiple motivations (question 22) researchers identified a broad range of motivations for engaging with Indigenous communities (Figure 4). When asked to identify their top (one) motivation (question 23), the most common was seeking mutual benefits for research and Indigenous communities (46\%) 


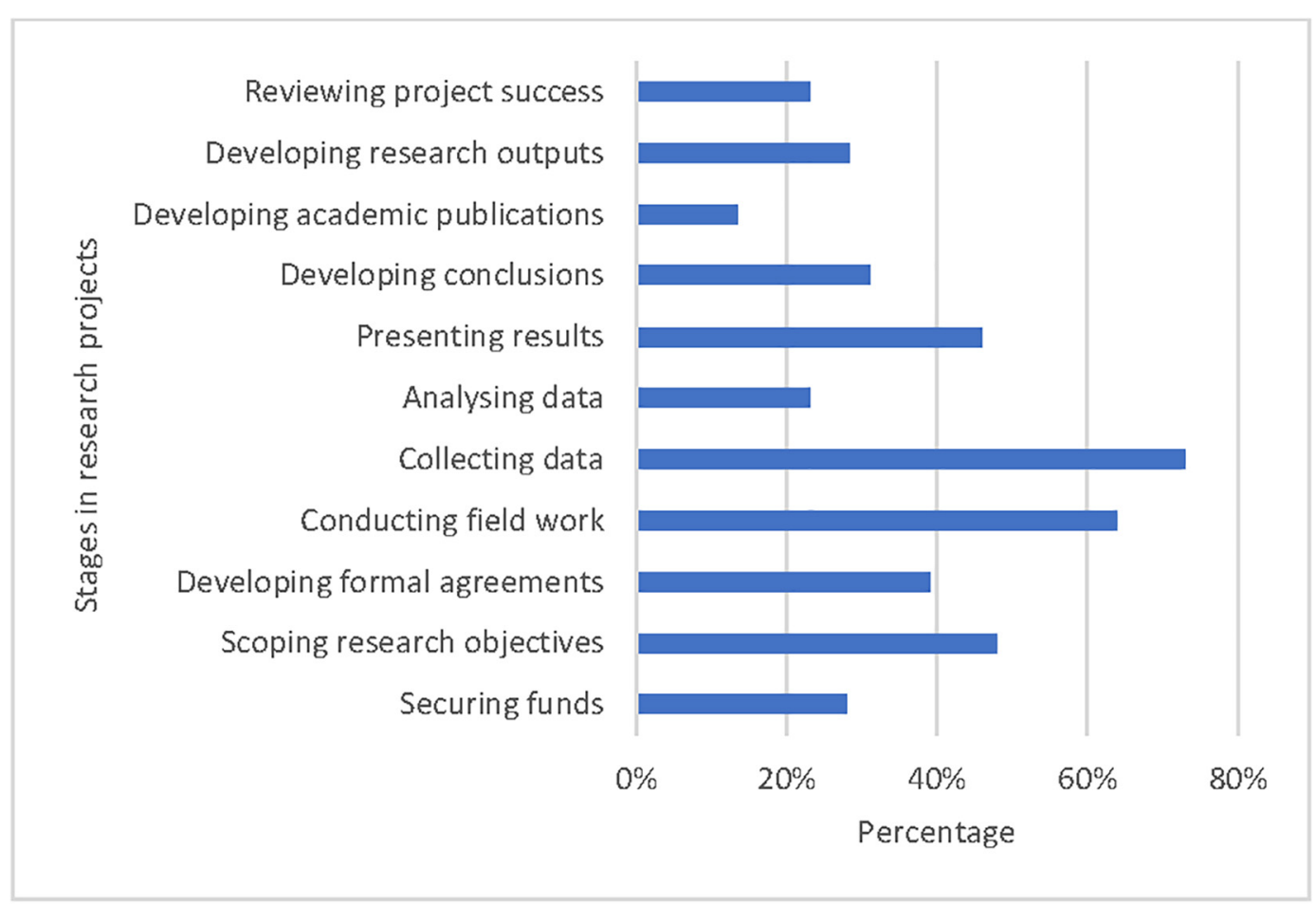

FIGURE 3 | Researchers' focus on Indigenous engagement in stages of marine research projects measured as percentage of survey respondents $(n=76)$.

TABLE 1 | Fixed effects for logit model explaining marine researcher engagement with Aboriginal and/or Torres Strait Islander communities.

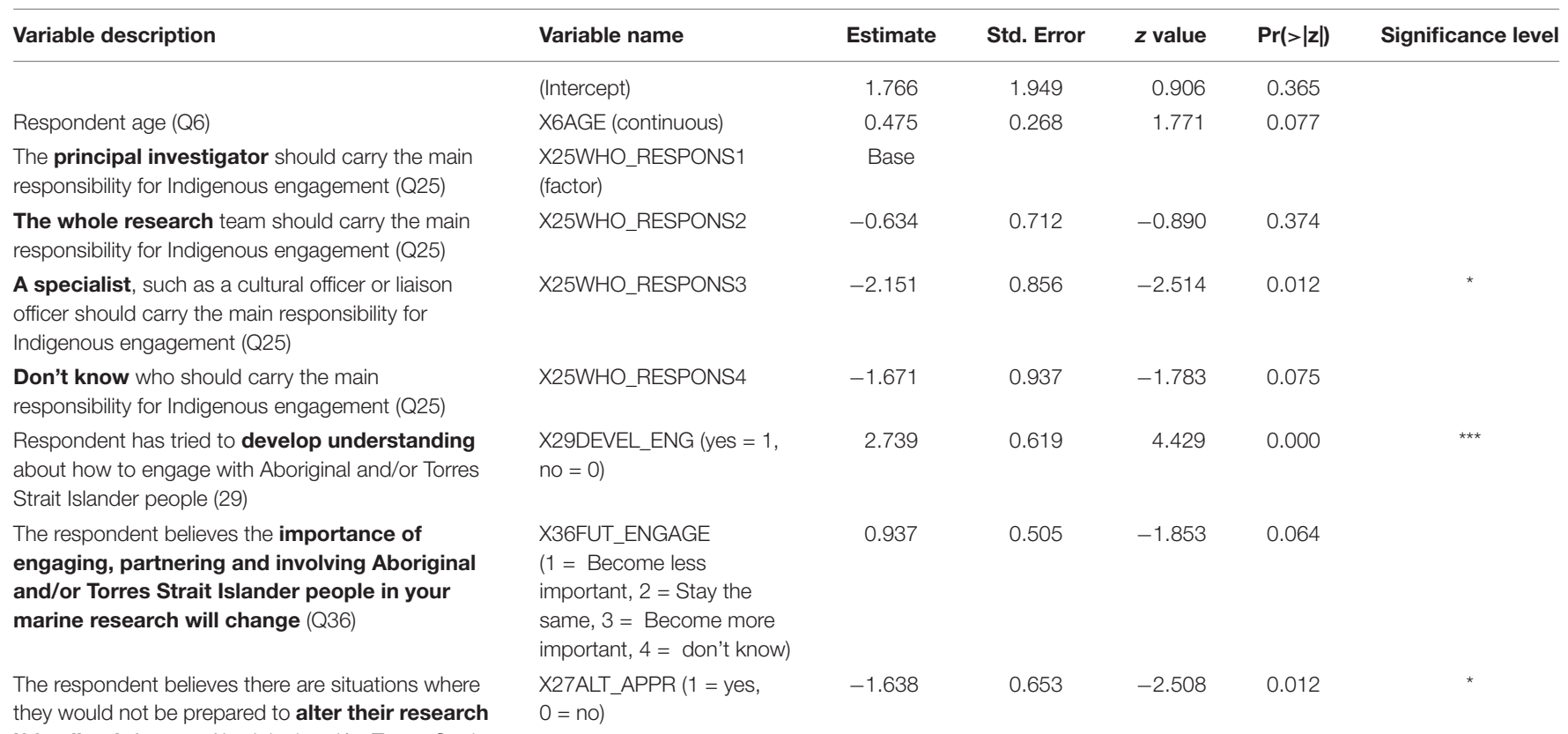

if feedback from an Aboriginal and/or Torres Strait Islander person included a request for change (Q26)

Brackets in first column indicate link to question number in survey. Significance codes: ${ }^{* * *} 0.001,{ }^{*} 0.05$. Model statistics: Number of observations 101 (those with missing values were deleted from the analysis). $A I C=100.35 B I C=123.9$, logLik $=-41.2$, deviance $=82.3$, df.resid $=92$.

followed by improving outcomes from research $(25 \%)$ and interest and willingness to build long-term relationships with communities for future research (15\%). Research ethics and career development benefits were of lesser importance to survey respondents when it concerns motivating factors for Indigenous engagement (Figure 4). 
TABLE 2 | Single term deletions test for main effects for logit model to explaining marine researcher engagement with Aboriginal and/or Torres Strait Islander communities (see Table 1 for variable description).

\begin{tabular}{|c|c|c|c|c|c|}
\hline Variable name & Df & AIC & LRT & $\operatorname{Pr}(\mathrm{Chi})$ & $\begin{array}{c}\text { Significance } \\
\text { level }\end{array}$ \\
\hline$<$ none $>$ & & 100.35 & & & \\
\hline X6AGE & 1 & 101.63 & 3.281 & 0.070 & \\
\hline X25WHO_RESPONS & 3 & 102.86 & 8.510 & 0.037 & * \\
\hline X29DEVEL_ENG & 1 & 123.77 & 25.425 & 0.000 & 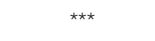 \\
\hline X36FUT_ENGAGE & 1 & 102.27 & 3.918 & 0.048 & * \\
\hline X27ALT_APPR & 1 & 105.69 & 7.336 & 0.007 & $\star \star$ \\
\hline
\end{tabular}

Significance level codes: ${ }^{* * *} 0.001,{ }^{* *} 0.01,{ }^{*} 0.05$. Model statistics scaled residuals: Min $=-3.7525,1 Q=-0.4126$, Median $=0.1794,3 Q=0.4733$, Max $=5.4435$.

The majority of respondents (84\%) indicated that they did not avoid the opportunity to engage Indigenous communities in marine research (question 21). The minority of respondents who had avoided engagement identified a lack of experience or not enough time or money as the reasons for their decisions. The majority $(80 \%)$ of researchers would be prepared to alter their approach to research if feedback from Indigenous communities requested a change (question 26) but 58\% of respondents indicated they would not if it was not scientifically robust to do so (question 27).

Respondent opinions appeared to be more divided in relation to their perceptions of who is responsible for Indigenous engagement (question 25) and whether or not all marine research requires Indigenous engagement (question 28). The most common responses for who should carry the main responsibility for engagement were the whole team $(37 \%)$, the principal investigator $(25 \%)$, and a specialist, such as a cultural officer or liaison officer (16\%). A comparison showed that those with engagement experience were less likely (95\% confidence level) to identify a cultural specialist as being responsible for carrying out Indigenous engagement than those with no experience. When asked "do you think all marine research projects require engagement with Indigenous people," $27 \%$ of respondents indicated no, $18 \%$ yes and 35\% were not sure. The question also drew a considerable number of comments identifying reasons why researchers did not think all research required engagement, the most common reasons were: research in deep sea or offshore marine environments, research where there is no clear connection to Indigenous interests, and research that is theoretical, desktop or laboratory based.

\section{Efforts and Interests to Improve Engagement}

Respondents were asked questions about the future importance of Indigenous engagement (question 36), motivations for engagement (questions 23-23), different approaches to develop understanding (questions 30-31), and their interest in learning opportunities about how to engage with Indigenous communities in culturally appropriate ways (question 34). Understanding researchers' perceptions about the future importance of engagement provides constructive insights (e.g., to challenges and opportunities) to other parties with interests and responsibilities (e.g., Indigenous organizations and research institutions) for promoting and guiding ethical and culturally appropriate engagement. The majority (63\%) of respondents indicated that engaging, partnering and involving Indigenous communities will become more important in the future, a further $20 \%$ indicated it would stay the same (i.e., as it was at the time of the survey). None of the respondents thought it would become less important in the future. More than two thirds of respondents are primarily motivated to engage by factors that would benefit Indigenous communities including, seeking mutual benefits (44\%), building long-term relationships (14\%) and equitable engagement based on co-management of resources (10\%). The majority $(66 \%)$ of respondents have tried to develop their understanding about

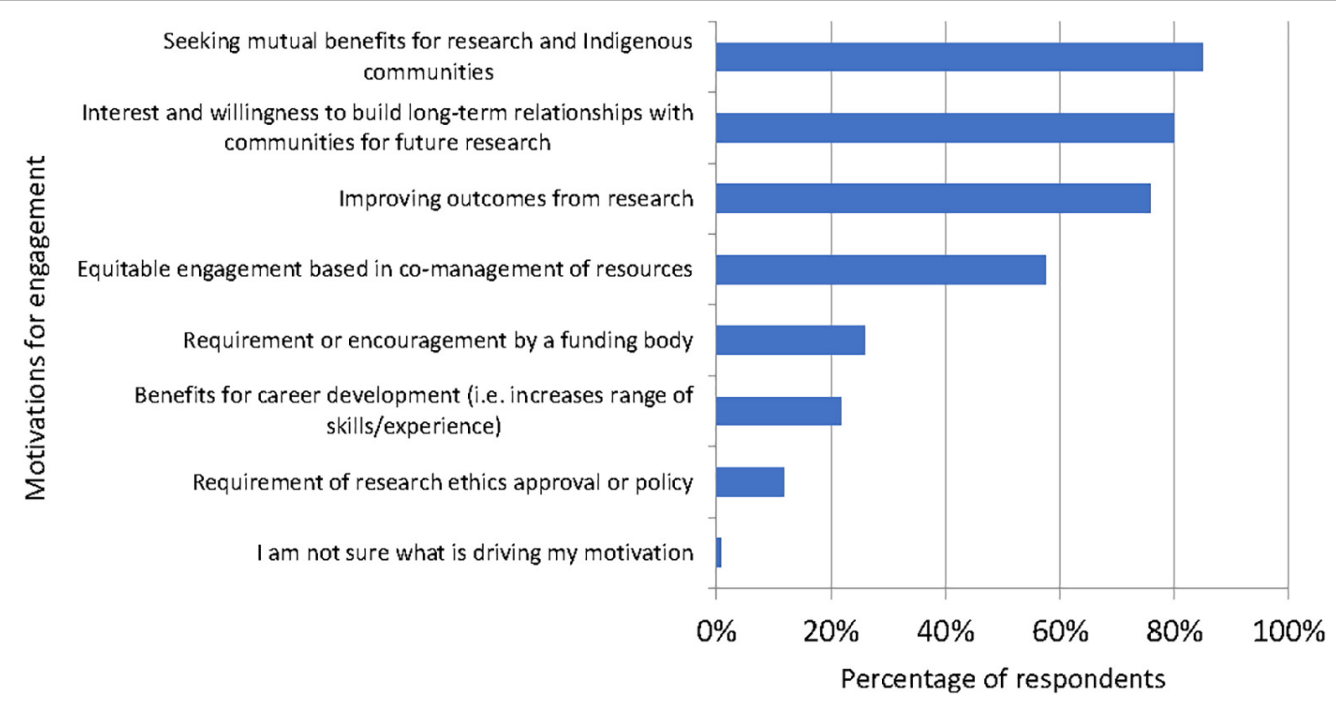

FIGURE 4 | Researchers' motivations for engaging Indigenous communities in marine science measured as a percentage of survey respondents ( $n=120$ ). 
how best to engage with Indigenous communities and indicated a diverse range of approaches (Figure 5). The three most useful approaches to develop understanding were discussions with experienced research colleagues (30\%), Indigenous organizations or representative bodies (29\%), and receiving feedback from Indigenous communities they had worked with (16\%). Interestingly, employer documents, academic literature, and human ethics research documents on Indigenous engagement were least favored by respondents for developing understanding. Indigenous community engagement protocols were identified as useful by $30 \%$ of respondents but only $4 \%$ identified them as most useful, even though the vast majority (82\%) of respondents indicated they were aware of cultural protocols and that they differ between Indigenous communities.

The vast majority ( $80 \%)$ of respondents indicated they would benefit from learning opportunities about how to engage in culturally appropriate ways (question 34). Respondents indicated most preferred ways to receive information on engaging were in a workshop setting where the workshop was run by Indigenous people (52\%) either on or off country (Figure 6).

\section{DISCUSSION AND CONCLUSION}

Our study indicates a positive aspirational response by Australia's marine researchers at various research institutions on the need to engage Aboriginal and Torres Strait Islander people in marine research. It also identifies a number of challenges for marine research institutions, marine researchers and Indigenous communities if positive aspirations for engagement are to be matched with respectful and effective engagement that delivers mutual benefits. Although there are signs of growth and maturation in inclusive marine research in Australia (e.g., Carter, 2008; Grech et al., 2014; Jackson et al., 2015; Dale et al., 2016; Simpendorfer et al., 2016; Austin et al., 2017) results from our study suggest the majority of engagements could be considered consultation or passive participation (as described in Carter, 2008) where participation was largely confined to a few specific stages in the research process.

While aspirational motivation to engage is an important element of the overall shift to improve Indigenous engagement in marine research it needs to be accompanied by informed decision making to design the research for culturally appropriate Indigenous engagement, including when and how to engage. The Guidelines for Ethical Research in Australian Indigenous Studies (AIATSIS, 2012) state it is essential that Indigenous people are full participants in research projects that concern them. Nakata (2011) points out that the AIATSIS Guidelines are a reminder that even where research may not involve human participants directly as a subject of research, all research in Indigenous contexts has a human and social aspect or impact and therefore must include Indigenous peoples as participants in the process. Our data suggest there is considerable uncertainty among Australia's marine researchers about what research projects

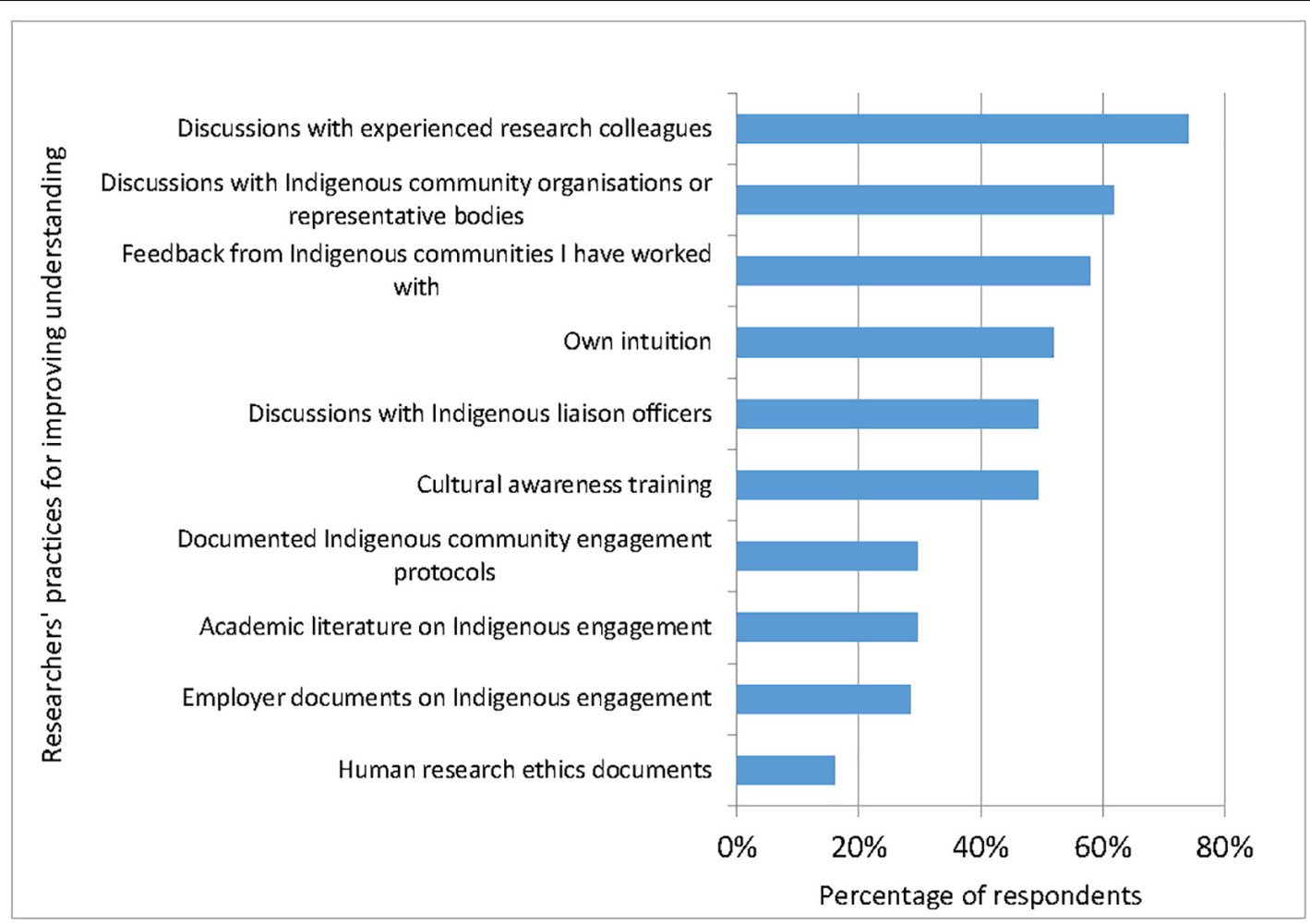

FIGURE 5 | Researchers' practices for developing understanding of engagement with Aboriginal and Torres Strait Islander people measured as a percentage of survey respondents $(n=81)$. 


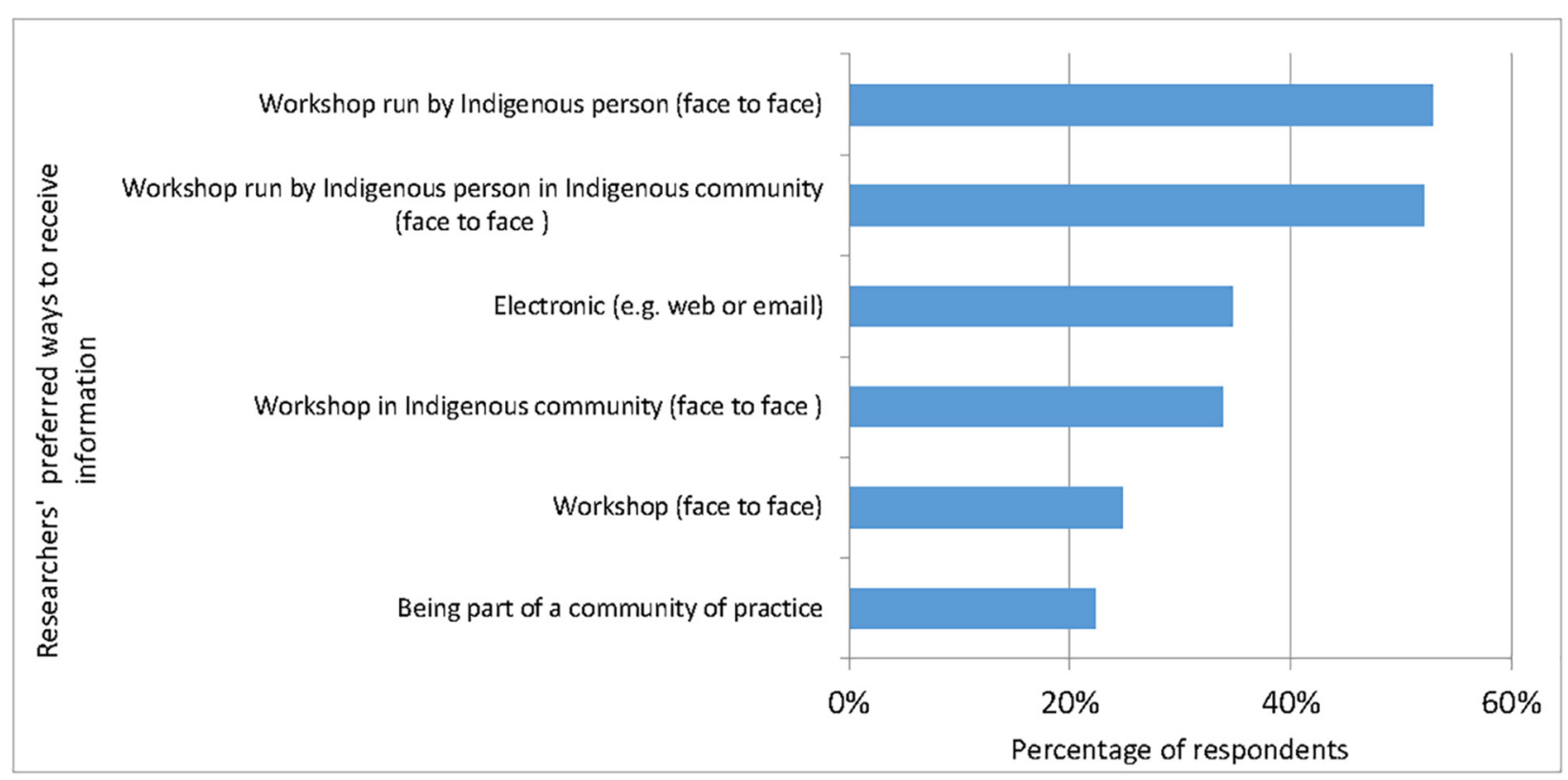

FIGURE 6 | Researchers' preferred ways for receiving information on engaging with Aboriginal and Torres Strait Islander people measured as a percentage of survey respondents $(n=121)$.

require Indigenous engagement (i.e., what projects concern Australian Aboriginal and Torres Strait Islander people given interests, priorities, aspirations and rights). More than a third of survey respondents were unsure if all marine research projects require Indigenous engagement while 18\% think that all research projects should have engagement. Our results suggest there is a challenge for both marine research institutions and Indigenous organizations to work together to improve clarity, particularly for marine science project leaders, about what marine research is of concern to Indigenous communities. For example, provision of centralized, accessible information systems to help researchers make informed and consistent decisions about whether or not their project is of concern to Indigenous people and requires engagement. A recent step in this direction is the 20 year review of the AIATSIS Guidelines and subsequent release of the draft AIATSIS Code of Ethics for Aboriginal and Torres Strait Islander Research (AIATSIS, 2019). The draft code is a more detailed document than its predecessor including greater clarity about the research that concerns or impacts Aboriginal and Torres Strait Islander peoples, when ethical review is required and the responsibilities of researchers. After the code is finalized, research institutions can take this a step further by ensuring they have appropriate institutional processes for checking and approving projects.

Smith (1999) and Fitzpatrick et al. (2017) point out that research with Indigenous communities has not always responded to community-identified priorities nor accommodated local Indigenous cultural protocols. These assertions relate to another challenge focused on the need to provide more effective support and due diligence to guide the researchers' engagement efforts with building community relevant research. Our results showed that employer provided documentation on Indigenous engagement were least favored for developing understanding about engagement and were not perceived as very useful. Carter (2008) points out that many agency-based principles and protocols in Australia are generic in nature with little practical guidance. Woodward and McTaggart (2016) point out it is very important for researchers to respect cultural protocols, which are unique to each Aboriginal and Torres Strait Islander language group and location. Our results showed that while the majority of marine researchers are aware of cultural engagement protocols, they are not favored as a tool to develop understanding of engagement with Indigenous Australians. These may be disturbing findings if marine research institutions and Indigenous organizations are assuming their documents are important for instigating and guiding researchers' efforts in engagement. Researchers instead expressed clear preference for discussions and feedback from experienced colleagues, Indigenous communities or representative bodies to learn whether their engagement was appropriate and how to best build collaborations. Research institutions and Indigenous communities can enhance engagement by recognizing researchers' past practices for improving understanding and preferred ways of receiving information. For example, employing Indigenous partnership coordinators to broker engagement within specific local and regional contexts, facilitate co-development of research, foster a culture of feedback to promote two-way learnings and advise on cross-cultural training. A shift in this direction will help move institutions away from approaches based around willing individuals in a project team toward a future where many people connect to provide culturally appropriate and ethical engagement including leaders, 
elders, scholars, managers, scientists, and ethics committee members. Some marine research institutions in Australia (e.g., the Australian Institute of Marine Science) have already employed Indigenous partnership coordinators to forge and maintain relationships with Aboriginal and Torres Strait Islander communities. Research institutions can also establish incentives or provide reward for experienced researchers who effectively mentor researchers with little or no experience in Indigenous engagement. Incentives could include allocating time for both parties involved in mentoring and formally establishing an Indigenous engagement mentoring initiative.

Jones et al. (2008) and Grech et al. (2014) point out that establishing and maintaining trusted and respectful relationships is important to effective engagement of Indigenous people in marine research in Australia. These requirements have also been reported by researchers focused on engagement in other countries (e.g., Drew, 2005; Shakeroff and Campbell, 2007; Castleden et al., 2010; Koster et al., 2012) and in other research disciplines, including human health and medicine (e.g., Jamieson et al., 2012; Fitzpatrick et al., 2017), water and land management (e.g., Ens et al., 2012; Escott et al., 2015; Woodward and McTaggart, 2016; Lynch, 2017), climatology (e.g., Green et al., 2010) and archaeology (e.g., Mitchell et al., 2013). Carter (2008) indicates that engaging Indigenous communities in the whole research process is central to effective Indigenous engagement and forming equitable research partnerships, but in Australia environmental sciences are yet to embed Indigenous engagement into their paradigms. Our research suggests that Indigenous communities are mostly involved in collecting data and doing field work in Australian marine research. The apparent oversights in the other stages of research, such as securing research funding, project scoping, developing formal research agreements, developing conclusions from research and reviewing project success indicate there is considerable scope to improve Indigenous engagement in marine research in Australia, especially if the aims include developing respectful relationships and Indigenous research leaders.

Ongoing reflection and discussion of research by both the scientific community and Indigenous people is important for ensuring transparent and open progression of the research process (McTaggart, 1997; Reason and Bradbury, 2001; Lynch, 2017). Reflections bring forth the inherent frustrations that can happen from both ends, where community members get frustrated by researchers overlooking aspects and researchers get frustrated that a smooth and linear progress is not available, particularly when reflection cannot be achieved with the limited time period set for the project. Partnerships are strengthened and trust is built by understanding and adapting to the evolving nature of engagement both within projects and the gaps between them. For example, in the gap periods between projects research institutions can maintain partnerships and build trust with Indigenous communities by ensuring lessons are learnt from previous projects and understanding about research needs and priorities is current, accessible and promoted.

There is a number of opportunities in Australia to advance toward the UN benchmarks for Indigenous engagement and participation in marine research. Perhaps the biggest opportunity is to leverage the positive aspirations among the majority of Australian marine scientists (as indicated by our survey results) and convert this to respectful, effective engagement that delivers mutually beneficial outcomes for researchers and Indigenous Australians. Our results point to a lack of culturally appropriate training for marine researchers. Carter (2008) identifies the importance of crosscultural awareness training for researchers but notes the irony that it is often implemented for Australian overseas projects but less so for projects operating on Aboriginal land in Australia. Australian marine research institutions and their managers can grasp this opportunity by increasing investment in culturally appropriate training that includes interactions with experienced researchers and Indigenous people, they also need to provide materials containing practical advice on what research is of concern to Indigenous people and how to plan and execute Indigenous engagement at all stages of the research process. Furthermore, that appropriate institutional processes are established to ensure researchers are fulfilling their responsibilities, in particular that their research addresses the concerns or impacts (both positive and negative) on Aboriginal and Torres Strait Islanders peoples and ethical review is conducted when required.

There are also opportunities to enhance the way research institutions and Indigenous organizations work together to help researchers forge and maintain respectful relationships and increase clarity about research that is relevant and of priority to Indigenous communities. Research organizations can establish strategic arrangements to forge and support long-term partnerships with Indigenous communities to identify and advance opportunities and ensure that mutually agreed co-design is consistently adopted, rather than arrangements only characterized by goodwill and the actions of a few experienced researchers. Strategic arrangements could include provision for objectives, targets and indicators designed to improve performance in areas such as use of local or regional engagement protocols, cross cultural training for researchers, two-way reflective learning from conducted research and access to useful information about the interests, aspirations and priorities of Indigenous communities.

Improving understanding about perceptions, motivations and practices for Indigenous engagement helps to piece together the underlying elements that unite to produce mutual research benefits. Many elements need to come together before the full spectrum of research benefits are actualised. For the marine science sector in Australia to be positioning itself for better cross-cultural engagement, it needs to be regularly reviewing performance to understand if it is meeting the rising benchmarks that communities, research institutions, national and international bodies are setting for the conduct of research. This means the research sector needs to be dynamic and adjust its behavior in a timely manner to keep up with the many drivers of change that shape engagement with Indigenous people. Our study was designed to generate empirical information from marine scientists on their engagement with 
Indigenous communities. The views of Aboriginal and Torres Strait Islander people on engagement in marine science were not specifically addressed in this study, it is important that empirical information on their views is also collected to provide a more complete national picture. This information is important for developing a cross-cultural, two-way perspective on the empirical evidence-base for perceptions, motivations and practices for Indigenous engagement in marine science in Australia. Finally, personal commitment by researchers engaging with Indigenous communities (e.g., going beyond what is expected of them by their institution by developing meaningful, long-term and genuine relationships) is rarely made explicit in the literature (Woodward and McTaggart, 2016). Researchers making these types of commitments should be recognized by their employers and rewarded (e.g., with career advancement and formal acknowledgements) to promote both short and longterm engagements.

\section{Conclusion}

The results of the survey indicate that Australia's marine researchers need to and are willing to improve performance for engaging Indigenous people in their research. Importantly this will come about most rapidly through informed, direct engagement. Australia's marine researchers have been very effective at informing and preparing themselves for engagement with a broad range of stakeholders from marine industries to conservation groups, now is the time to demonstrate the same level of wide-spread professionalism for engaging Aboriginal and Torres Strait Islander people. We recommend that this survey be repeated in 5 years, preferably with a larger number of survey participants, and a complementary survey is established to generate empirical information gathered from Indigenous communities.

\section{DATA AVAILABILITY STATEMENT}

The datasets generated for this study will not be made publicly available. The datasets are categorized as private to protect the identity of survey respondents. Requests to access the datasets should be directed to the corresponding author.

\section{REFERENCES}

AIATSIS (2012). Guidelines for Ethical Research In Australian Indigenous Studies. Canberra: Australian Institute of Aboriginal and Torres Strait Islander Studies.

AIATSIS (2019). Consultation Draft Of The AIATSIS Code of Ethics for Aboriginal and Torres Strait Islander Research (AIATSIS Code of Ethics). Canberra: Australian Institute of Aboriginal and Torres Strait Islander Studies.

AIMS (2020). Indigenous Engagement Strategy. Available online at: https://www. aims.gov.au/indigenous-partnerships (accessed March 2020).

Austin, B. J., Vigilante, T., Cowell, S., Dutton, I. M., Djanghara, D., Mangolomara, S., et al. (2017). The Uunguu monitoring and evaluation committee: intercultural governance of a land and sea management programme in the Kimberley, Australia. Ecol. Manag. Restor. 18, 124-133. doi: 10.1111/emr.12257

Australian Government (2012). Marine Bioregional Plan for the South-west Marine Region. Canberra: Australian Government.

\section{ETHICS STATEMENT}

The studies involving human participants were reviewed and approved by CSIRO Social Science Human Research Ethics Committee (137/16). The patients/participants provided their written informed consent to participate in this study.

\section{AUTHOR CONTRIBUTIONS}

PH: primary role as overall research leader providing objectives, leadership and coordination to design and complete the survey and communicate the survey results. The primary manuscript writer. EP: primary role in survey design and ethics approval, including developing and testing the survey, and data analysis. Role in development of manuscript. $\mathrm{CH}$ : role in developing survey, interpreting results and developing manuscript, providing both a scientific and Indigenous perspective. MF: role in developing survey, interpreting results and developing manuscript, providing both a scientific and Indigenous perspective. All authors contributed to the article and approved the submitted version.

\section{FUNDING}

This research and manuscript was supported by the Marine Biodiversity Hub funded by the Australian Government's National Environmental Science Program. This program provided the funding for the research, manuscript development and for open access publication fees.

\section{SUPPLEMENTARY MATERIAL}

The Supplementary Material for this article can be found online at: https://www.frontiersin.org/articles/10.3389/fmars. 2020.00522/full\#supplementary-material

Australian Government (2014). National Environmental Science Programme Indigenous Engagement and Participation Strategy Guidelines v1.0, Commonwealth of Australia. Canberra: Australian Government.

Australian Government (2018). Australian Marine Parks: South-west Marine Parks Network Management Plan. Canberra: Australian Government.

Ayre, M., and Mackenzie, J. (2013). Unwritten, unsaid, just known: the role of indigenous knowledge(s) in water planning in Australia. Local Environ. 18, 753-768. doi: 10.1080/13549839.2012.665864

Bainbridge, R., Tsey, K., McCalman, J., Kinchin, I., Saunders, V., Lui, F. W., et al. (2015). No one's discussing the elephant in the room: contemplating questions of research impact and benefit in aboriginal and Torres Strait islander Australian health research. BMC Public Health 15:696. doi: 10.1186/s12889015-2052-3

Bates, D., Maechler, M., Bolker, B., Walker, S., Christensen, R. H. B., Singmann, H., et al. (2014). Ime4: Linear Mixed-Effects Models Using Eigen and S4. 
$R$ Package Version 1.0-6. Available online at: https://cran.r-project.org/web/ packages/lme4/index.html (accessed January 24, 2019).

Bohensky, E. L., Butler, J. R. A., and Davies, J. (2013). Integrating indigenous ecological knowledge and science in natural resource management: perspectives from Australia. Ecol. Soc. 18:20. doi: 10.5751/es-05846-180320

Carter, J. L. (2008). Thinking outside the framework: equitable research partnerships for environmental research in Australia. Geograph. J. 174, 63-75. doi: $10.1111 / \mathrm{j} .1475-4959.2007 .00251 . \mathrm{x}$

Castleden, H., Morgan, V. S., and Neimanis, A. (2010). Researchers' perspectives on collective/community co-authorship in community-based participatory indigenous research. J. Empir. Res. Hum. Res. Ethics 5, 23-32. doi: 10.1525/jer. 2010.5.4.23

Convention on Biological Diversity (2011). The Tkarihwaieé:ri: Code of Ethical Conduct Ensure Respect for the Cultural and Intellectual Heritage of Indigenous and Local Communities. Montreal: Secretariat of the Convention on Biological Diversity.

Crook, D. A., Douglas, M. M., King, A. J., and Schnierer, S. (2016). Toward deeper collaboration: stories of Indigenous interests, aspiration, partnerships and leadership in aquatic research and management. Rev. Fish Biol. Fish. 26, 611-615. doi: 10.1007/s11160-016-9449-7

CSIRO (2020). Indigenous Engagement Strategy. Canberra: CSIRO.

Dale, A., George, M., Hill, R., and Fraser, D. (2016). Traditional Owners and Sea Country in the Southern Great Barrier Reef - Which Way Forward?. Report to the National Environmental Science Programme. Cairns: Reef and Rainforest Research Centre Limited.

Dhimurru Aboriginal Corporation (2013). Dhimurru IPA Sea Country Management Plan 2013 to 2015. Nhulunbuy: Dhimurru Aboriginal Corporation.

Dobbs, R. J., Davies, C. L., Walker, M. L., Pettit, N. E., Pusey, P. J., Close, P. G., et al. (2016). Collaborative research partnerships inform monitoring and management of aquatic ecosystems by indigenous rangers. Rev. Fish Biol. Fish. 26, 711-725. doi: 10.1007/s11160-015-9401-2

Drew, J. (2005). Use of traditional ecological knowledge in marine conservation. Conserv. Biol. 19, 1286-1293. doi: 10.1111/j.1523-1739.2005.00158.x

Ens, E. J., Finlayson, M., Preuss, K., Jackson, S., and Holcombe, S. (2012). Australian approaches for managing 'country' using Indigenous and nonIndigenous knowledge. Ecol. Manag. Restor. 13, 100-107. doi: 10.1111/j.14428903.2011.00634.x

Escott, H., Beavis, S., and Reeves, A. (2015). Incentives and constraints to Indigenous engagement in water management. Land Use Policy 49, 382-393. doi: 10.1016/j.landusepol.2015.08.003

Fitzpatrick, E. F. M., McDonald, G., Martiniuk, A. L., D’Antoine, H., Oscar, J., and Carter, M. (2017). The picture talk project: starting a conversation with community leaders on research with remote aboriginal communities of Australia. BMC Med. Ethics 18:34. doi: 10.1186/s12910-017-0191-z

FRDC (2013). Indigenous Research Priorities Endorsed. Canberra: Fisheries Research and Development Corporation.

Grech, A., Parra, G. J., Beasley, I., Bradley, J., Johnson, S., Whiting, S., et al. (2014). Local assessments of marine mammals in cross-cultural environments. Biodiver. Conserv. 23, 3319-3338. doi: 10.1007/s10531-014-0800-9

Green, D., Billy, J., and Tapim, A. (2010). Indigenous Australians' knowledge of weather and climate. Clim. Chang. 100, 337-354. doi: 10.1007/s10584-0109803-z

Hill, R., Grant, C., George, M., Robinson, C. J., Jackson, S., and Abel, N. (2012). A typology of indigenous engagement in australian environmental management: implications for knowledge integration and social-ecological system sustainability. Ecol. Soc. 17:123. doi: 10.5751/ES-04587-170123

Hill, R., Pert, P. L., Davies, J., Robinson, C. J., Walsh, F., and Falco-Mammone, F. (2013). Indigenous Land Management In Australia: Extent, Scope, Diversity, Barriers And Success Factors. Cairns: CSIRO Ecosystem Sciences.

Hosmer, D. W., Lemeshow, S., and Sturdivant, R. X. (2013). Applied Logistic Regression, 3rd Edn, Hoboken, NJ: John Wiley \& Sons.

IPBES (2017). Plenary of the Intergovernmental Science-Policy Platform on Biodiversity and Ecosystem Services. Fifth session. Deliverable 1c: Information on Work Related To Indigenous And Local Knowledge Systems. Bonn: IPBES.

Jackson, M. V., Kennett, R., Bayliss, P., Warren, R., Waina, N., Adams, J., et al. (2015). Developing collaborative marine turtle monitoring in the Kimberley region of northern Australia. Ecol. Manag. Restor. 16, 163-176. doi: 10.1111/ emr.12184

Jackson, S., Tan, P., Mooney, C., Hoverman, S., and White, I. (2012). Principles and guidelines for good practice in Indigenous engagement in water planning. J. Hydrol. 474, 57-65. doi: 10.1016/j.jhydrol.2011.12.015

Jackson, W. J., Argent, R. M., Bax, N. J., Clark, G. F., Coleman, S., Cresswell, I. D., et al. (2017). Australia State Of The Environment 2016: Overview, Independent Report To The Australian Government Minister for the Environment and Energy, Australian Government Department of the Environment and Energy, Canberra. Available online at: https://soe.environment.gov.au/sites/default/files/soe2016overview-launch-version328feb17.pdf?v=1488792535 (accessed January 24, 2019).

Jamieson, L. M., Paradies, Y. C., Eades, S., Chong, A., Maple-Brown, L., Morris, P., et al. (2012). Ten principles relevant to health research among indigenous Australian populations. Med. J. Austr. 197, 16-18. doi: 10.5694/mja11.11642

Janke, T., and Sentina, M. (2018). Indigenous Knowledge: Issues for Protection and Management, IP Australia, Commonwealth of Australia. Available online at: https://www.ipaustralia.gov.au/sites/default/files/ipaust_ikdiscussionpaper_ 28march2018.pdf (accessed March 2020).

Jones, A., Barnett, B., Williams, A. J., Grayson, J., Busilacchi, S., Duckworth, A., et al. (2008). Effective communication tools to engage Torres Strait islanders in scientific research. Continent. Shelf Res. 28, 2350-2356. doi: 10.1016/j.csr.2008. 03.027

Koster, R., Baccar, K., and Lemelin, H. (2012). Moving from research on, to research with and for indigenous communities: a critical reflection on community-based participatory research. Can. Geograph. 56, 195-210. doi: 10.1111/j.1541-0064. 2012.00428.x

Lincoln, G., Austin, B. J., Dobbs, R. J., Mathews, D., Oades, A., Wiggan, S., et al. (2017). Collaborative Science on Kimberley Saltwater Country -A Guide for Researchers V17.03. Prepared by the Kimberley Land Council for the Kimberley Indigenous Saltwater Science Project. Crawley, WA: Western Australian Marine Science Institute.

Lynch, A. J. J. (2017). Respect, reflect, and engage - enhancing biophysical research practices with Indigenous people, their land, and culture. Austr. J. Environ. Manag. 24, 319-331. doi: 10.1080/14486563.2017.1349694

McTaggart, R. (1997). Participatory Action Research; International Contexts and Consequences. Albany: State University of New York Press.

Mitchell, M., Guilfoyle, D. R., Reynolds, R., and Morgan, C. (2013). Towards sustainable community heritage management and the role of archaeology: a case study from Western Australia. Heritage Soc. 6, 24-45. doi: 10.1179/ 2159032X13Z.0000000005

Nakata, N. M. (2011). Report on Torres Strait Fisheries Research Protocols: A Guide for Researchers. A Report Commissioned By The Torres Strait Scientific Advisory Committee. Available online at: https:/www.pzja.gov.au/sites/g/ files/net4491/f/content/uploads/2011/06/2011-Nakata-Nakata-Report-onTorres-Strait-Fisheries-Research-Protocols_ISBN.pdf (accessed January 24, 2019).

National Marine Science Committee (2015). National Marine Science Plan 20152025 - Driving the Development of Australia's Blue Economy. Coffs Harbour, NSW: National Marine Science Committee.

Nursey-Bray, M., and Jacobson, C. (2014). 'Which way?': the contribution of indigenous marine governance. Austr. J. Maritime Ocean Aff. 6, 27-40. doi: $10.1080 / 18366503.2014 .888136$

Pilbara Indigenous Marine Reference Group (2010). Pilbara Sea Country Plan. Yamatji Marlpa Aboriginal Corporation. Available online at: http: //ymac.org.au/wp-content/uploads/2013/11/PilbaraSeaPlan_FinalReport.pdf (accessed January 24, 2019).

Reason, P., and Bradbury, H. (2001). Handbook of Action Research. London: Sage. Rigney, L. (2001). A First Perspective of Indigenous Australian Participation in Science: Framing Indigenous research towards Indigenous Australian Intellectual Sovereignty. Available online at: https://ncis.anu.edu.au/_lib/doc/LI_Rigney_ First_perspective.pdf (accessed January 24, 2019).

Shakeroff, J. M., and Campbell, L. M. (2007). Traditional ecological knowledge in conservation research: problems and prospects for their constructive engagement. Conserv. Soc. 5, 343-360.

Simpendorfer, C. A., Kyne, P. M., Noble, T. H., Goldsbury, J., Basiita, R. K., Lindsay, R., et al. (2016). Environmental DNA detects, critically endangered 
largetooth sawfish in the wild. Endang. Spec. Res. 30, 109-119. doi: 10.3354/esr 00731

Sithole, B. (2012). The ARPNet Dilly Bag - A Practical Field Guide To Participatory and Other Research Tools For Use by Aboriginal Research Practitioners in Australia. Casuarina, NT: Charles Darwin University.

Smith, L. T. (1999). Decolonising Methodologies: Research and Indigenous Peoples. London: Zed Books Ltd.

Smyth and Bahrdt Consultants (2004). Kooyang Sea Country Plan. A Report for the Framlingham Aboriginal Trust and Winda Mara Aboriginal Corporation. Available online at: https://parksaustralia.gov.au/marine/pub/scientificpublications/archive/kooyang-plan05.pdf (accessed January 24, 2019).

Thaman, R., Lyver, P., Mpande, R., Perez, E., Cariño, J., Takeuchi, K., et al. (eds) (2013). The Contribution of Indigenous and Local Knowledge Systems to IPBES: Building Synergies with Science. IPBES Expert Meeting Report, UNESCO/UNU. Paris: UNESCO.

UNESCO (2018). UNESCO Policy On Engaging With Indigenous Peoples. 201 EX/6. Paris: United Nations Educational, Scientific and Cultural Organization.
United Nations (2008). Declaration on the Rights of Indigenous Peoples. United Nations.

Woodward, E., and McTaggart, P. M. (2016). Transforming cross-cultural water research through trust, participation and place. Geograph. Res. 54, 129-142. doi: $10.1111 / 1745-5871.12136$

Conflict of Interest: The authors declare that the research was conducted in the absence of any commercial or financial relationships that could be construed as a potential conflict of interest.

Copyright (c) 2020 Hedge, van Putten, Hunter and Fischer. This is an open-access article distributed under the terms of the Creative Commons Attribution License (CC BY). The use, distribution or reproduction in other forums is permitted, provided the original author(s) and the copyright owner(s) are credited and that the original publication in this journal is cited, in accordance with accepted academic practice. No use, distribution or reproduction is permitted which does not comply with these terms. 